\title{
Study of clinical profile and indications of Permanent Pacemaker Insertion in Nepali population presenting to tertiary care centre in Nepal
}

\author{
Shovit Thapa', Ratna Mani Gajurel', Chandra Mani Poudel', Hemant Shrestha', Sanjeev Thapa', \\ Surya Devkota', Parash Koirala', Surya Pathak ${ }^{1}$
}

${ }^{1}$ Department of Cardiology, Manmohan Cardiothoracic Vascular and Transplant Centre, Kathmandu, Nepal.

Corresponding Author: Shovit Thapa,

Department of Cardiology

Manmohan Cardiothoracic Vascular and Transplant Centre, Kathmandu, Nepal.

Email: thapashovit@gmail.com

ORCID ID NO: 0000-0002-1888-4938

Cite this article as: Thapa S., Gajurel R. M., Paudel C. M., et al. Study of clinical profile and indications of Permanent Pacemaker Insertion in Nepali population presenting to tertiary care centre in Nepal. Nepalese Heart Journal 2019; Vol 16 (2), 47-52

Submission date: $23^{\text {rd }}$ May 2019

Accepted date: 31 st October 2019

Abstract

Background and Aims: Although pacemaker implantation has been done regularly in Nepal for the last 20 years, there is no large scale published data of pacemaker implantations. Manmohan Cardiothoracic Vascular and Transplant Centre (MCVTC) have been providing uninterrupted permanent pacemaker implantation services since its inception. This led us an opportunity to report the data regarding permanent pacemaker implantations in MCVTC.

Methods: Hospital records of all patients who had undergone PPI at MCVTC between Shrawan 2070 - Ashad 2075/ July 2013- June 2018 ( 5 years) were searched for and all available data were retrospectively analyzed.

Results: A total of 277 cases underwent PPI at MCVTC in 5 years. Out of these $165(59.5 \%)$ were male with male to female ratio of 1.47 . The mean age was $65.82 \pm 16.10$ years with $3(1.1 \%)$ cases of $<20$ years of age and almost $70 \%$ of cases aged $>60$ years. Dual chamber units were implanted in $49(17.7 \%)$ cases. Only 13 women $(11.6 \%)$ received dual chamber pacemaker compared with 36 men $(21.8 \%)(\mathrm{P}=0.029)$. The most common indication for PPI was complete atrioventricular block 165 $(59.6 \%)$ followed by sick sinus syndrome 65 (23.5\%). Hypertension 84 (30.3\%) was the most common co morbidity present. Complication occurred in $5.4 \%$ of cases with wound infection as commonest complication and single mortality due to postoperative complications post-RV repair.

Conclusion: Single chamber pacemaker was the most commonly used pacemaker. Dual chamber pacemaker was more common in younger patients. Complete heart block was the most common indication. Permanent pacemaker insertion was effective and relatively safe procedure in MCVTC with few complications.

Keywords: Complete Heart Block; Permanent Pacemaker Insertion; Sick sinus Syndrome.

DOl: https://doi.org/10.3126/njh.v16i2.26317

\section{Introduction}

Bradyarrhythmias are cause of sudden death and are the main indications for permanent pacemaker implantation (PPI). Pacemaker implantation is an accepted intervention which has been shown to relieve symptoms, improve the quality of life and reduce mortality in patients with bradyarrhythmias ${ }^{1,2}$. Permanent pacemaker technology and pacing techniques have advanced considerably since their inception in the late $1950 \mathrm{~s}^{3}$ and permanent pacing is now accepted as being highly cost-effective, safe, and relatively simple to perform with myriad features incorporated into the pacemaker design including programmability, telemetry and different modes of pacing ${ }^{4-8}$. Since its inception in April 2009, Manmohan Cardiothoracic, Vascular and Transplant Centre (MCVTC) has been established as a cardiac subspecialty centre and provides interventional services to referred cases from all over Nepal and since establishment of Cath Lab in 2013 there has been uninterrupted PPI services.

Although pacemaker implantation has been done regularly in

@ Nepalese Heart Journal. Nepalese Heart Journal retain copyright and works is simultaneously licensed under Creative Commons Attribution License CC - By 4.0 that allows others to share the work with an acknowledge of the work's authorship and initial publication in this journal

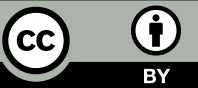


Nepal for the last 20 years, there is no large scale published data of pacemaker implantations. Few studies and reports have been published regarding clinical profile, short term outcome, experiences and gender differences in pacemaker implantation in different centre including MCVTC $^{9-13}$.

The objective of this study is to analyze the clinical profile and indications of permanent pacing in Nepali population presenting to MCVTC in 5 years time (2070 Shrawan to 2075 Ashad; July 2013June 2018).

\section{Methods}

This is hospital based, retrospective observational study conducted at department of cardiology, MCVTC, Maharajgunj, Kathmandu. Hospital records were taken as source of data and all patients who underwent PPI in between July 2013 to June 2018 were included. Non-Nepali individuals and those receiving pulse generator replacements were excluded from the study. Data were extracted from the hospital records without affecting the confidentiality of the patients and after approval from the institutional review board of institute of medicine. Hospital records were searched thoroughly for age, sex, diagnosis, indications of pacemaker insertion, type of pacemaker implanted and complications during hospital stay. Data were compiled, edited and checked to maintain consistency. Repetitions and omissions of data were corrected before coding and entering them in MS Excel. Recorded data were, then, exported to SPSS V.21.0 for further analysis. Descriptive statistics such as mean \pm standard deviation for continuous variables and percentages, ratios etc for categorical variables were computed. The associations between two categorical variables were assessed through the use of Chi-square test. Comparisons of continuous variable between two groups were carried out by independent t-test and across more than two groups were carried out by one way ANOVA test. The results were considered statistically significant if $\mathrm{p}<0.05$.

\section{Results}

A total of 277 cases underwent PPI at MCVTC in 5 years in the study period. Out of these $165(59.5 \%)$ were male and $112(40.5 \%)$ were female with male to female ratio of 1.47 . The mean age of total population at implant was $65.82 \pm 16.10$ years. The mean age of male cases was $65.91 \pm 16.02$ years and female was $65.61 \pm 16.29$ years. The minimum age was 8 years and maximum was 99 years with $3(1.1 \%)$ cases $<20$ years of age, almost $70 \%$ of cases aged $>60$ years and $51(18.4 \%)$ cases of aged $>80$ years. The distribution of cases was comparable for male and female for different age groups.

Table 1: Age Distribution of Patients with PPI

\begin{tabular}{|llll|}
\hline Age Group & $\begin{array}{l}\text { Total } \\
(\mathrm{n}-277)\end{array}$ & $\begin{array}{l}\text { Male } \\
(\mathrm{n}-165)\end{array}$ & $\begin{array}{l}\text { Female } \\
(\mathrm{n}-112)\end{array}$ \\
\hline$<20$ years & $3(1.1 \%)$ & $2(1.2 \%)$ & $1(0.9 \%)$ \\
\hline 21-30 years & $7(2.5 \%)$ & $4(2.4 \%)$ & $3(2.7 \%)$ \\
\hline 31-40 years & $12(4.3 \%)$ & $6(3.6 \%)$ & $6(5.3 \%)$ \\
\hline 41-50 years & $27(9.7 \%)$ & $17(10.3 \%)$ & $10(8.9 \%)$ \\
\hline 51-60 years & $41(14.8 \%)$ & $21(12.7 \%)$ & $20(17.8 \%)$ \\
\hline 61-70 years & $60(21.7 \%)$ & $38(23 \%)$ & $22(19.6 \%)$ \\
\hline $71-80$ years & $76(27.4 \%)$ & $45(27.3 \%)$ & $31(27.7 \%)$ \\
\hline$>80$ years & $51(18.4 \%)$ & $32(19.4 \%)$ & $19(17 \%)$ \\
\hline
\end{tabular}

Dual chamber pacemaker was implanted in $49(17.7 \%)$ cases, single chamber in $228(82.3 \%)$. Only 13 women $(11.6 \%)$ received dual chamber pacemaker compared with 36 men $(21.8 \%)(\mathrm{P}=$ 0.029). Moreover, dual chamber pacemakers were implanted in younger patients compared to older ones; mean age [dual chamber$55.51 \pm 16.29$ years Vs single chamber- $68.04 \pm 15.42$ years; $p<0.001]$. Out of total patients receiving dual chamber pacemakers, $71.5 \%$ were $<60$ years of age and only $28.5 \%$ were $>60$ years of age, although the

Table 2: Mean Age, Indication and Type of Pacemaker Implanted and Sex Distribution.

\begin{tabular}{|c|c|c|c|c|}
\hline & $\begin{array}{l}\text { Total } \\
\text { (n-277) }\end{array}$ & $\begin{array}{l}\text { Male } \\
(n-165)\end{array}$ & $\begin{array}{l}\text { Female } \\
(n-112)\end{array}$ & P-Value \\
\hline Age & $65.82 \pm 16.10$ & $65.91 \pm 16.02$ years & $65.61 \pm 16.29$ years & \\
\hline \multicolumn{5}{|c|}{ Pacemaker type implanted } \\
\hline Dual chamber & $49(17.7 \%)$ & $36(21.8 \%)$ & $13(11.6 \%)$ & 0.029 \\
\hline Single chamber & $228(82.3 \%)$ & $129(78.2 \%)$ & $99(88.4 \%)$ & \\
\hline \multicolumn{5}{|c|}{ Indication of Pacemaker Implantation } \\
\hline Complete Heart Block & $165(59.6 \%)$ & $109(66.1 \%)$ & $56(50 \%)$ & 0.005 \\
\hline Sick Sinus Syndrome & $65(23.5 \%)$ & $26(15.6 \%)$ & $39(34.8 \%)$ & $<0.001$ \\
\hline 2:1 AV Block & $23(8.3 \%)$ & $13(7.9 \%)$ & $10(8.9 \%)$ & 0.826 \\
\hline High Degree AV Block & $11(4.0 \%)$ & $9(5.5 \%)$ & $2(1.8 \%)$ & 0.125 \\
\hline Trifasicular Block & $6(2.2 \%)$ & $5(3.0 \%)$ & $1(0.9 \%)$ & 0.230 \\
\hline Bifasicular Block & $3(1.1 \%)$ & $2(1.2 \%)$ & $1(0.9 \%)$ & 0.801 \\
\hline Junctional Bradycardia & $4(1.5 \%)$ & $1(0.6 \%)$ & $3(2.7 \%)$ & 0.156 \\
\hline \multicolumn{5}{|c|}{ Mean age at Type of Pacemaker implantation } \\
\hline Dual chamber & & Single chamber & & p-value \\
\hline $55.51 \pm 15.28$ years & & $68.04 \pm 15.42$ years & & $<0.001$ \\
\hline
\end{tabular}


latter group comprised of almost $70 \%$ of total patients receiving PPI.

The most common indication for PPI was complete atrioventricular block (CHB) followed by sick sinus syndrome (SSS), 2:1 AV block, high-grade AV block, trifasicular block, junctional bradycardia and bifasicular block. CHB was more common in male patients compared to female (p-0.005) where as SSS was more common in female compared to male patients $(\mathrm{p}<0.001)$.

Figure 1: Indication of Permanent Pacemaker Implantation and Sex Distribution.

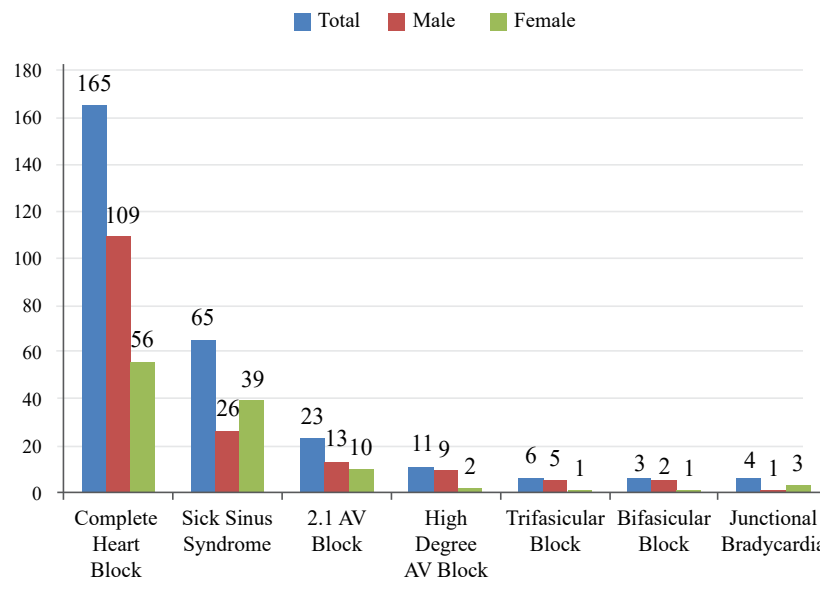

A total of $161(58.1 \%)$ cases had one or more co morbidities. Hypertension (HTN) was the most common co morbidity present followed by Diabetes mellitus (DM), post myocardial infarction (MI), chronic obstructive pulmonary disease, degenerative valvular heart disease, post cardiac surgery 16 (5.8\%), dilated cardiomyopathy and other ailments. Male cases undergoing PPI had more prevalence of Hypertension $(p=0.023)$, diabetes mellitus $(p=0.003)$ and post myocardial infarction $(\mathrm{p}=0.030)$ compared to female cases.

Figure 2: Complications in Patients Undergoing PPI

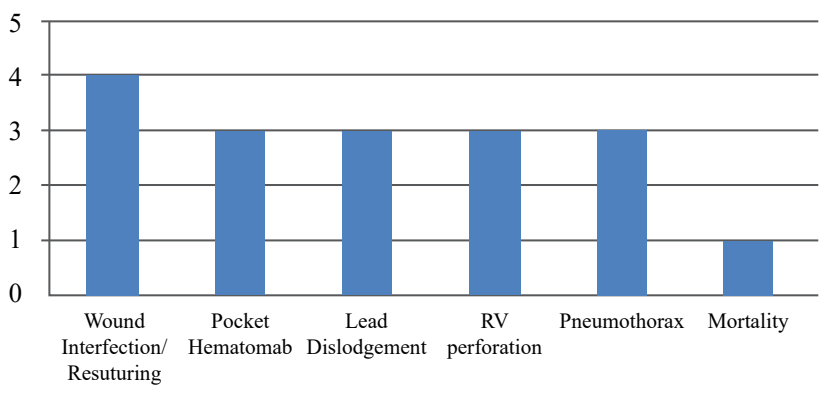

TABLE 3: Associated Co morbidities in patients with PPI

\begin{tabular}{|c|c|c|c|c|}
\hline & $\begin{array}{l}\text { Total } \\
(\mathrm{N}-277)\end{array}$ & $\begin{array}{l}\text { Male } \\
\text { (n-165) }\end{array}$ & $\begin{array}{l}\text { Female } \\
(n-112)\end{array}$ & p- Value \\
\hline Hypertension & $84(30.3 \%)$ & $58(35.1 \%)$ & $36(32.1 \%)$ & 0.023 \\
\hline Diabetes Mellitus & $30(10.8 \%)$ & $25(15.1 \%)$ & $5(4.5 \%)$ & 0.003 \\
\hline Post Myocardial Infarction & $24(8.7 \%)$ & $19(11.5 \%)$ & $5(4.5 \%)$ & 0.030 \\
\hline Chronic Obstructive Pulmonary Disease & $21(7.6 \%)$ & $10(6.0 \%)$ & $11(9.8 \%)$ & 0.176 \\
\hline Degenerative Valvular heart Disease & $16(5.8 \%)$ & $7(4.2 \%)$ & $9(8.0 \%)$ & 0.144 \\
\hline Post Cardiac Surgery & $16(5.8 \%)$ & $11(6.7 \%)$ & $5(4.5 \%)$ & 0.310 \\
\hline Dilated Cardiomyopathy & $11(4.0 \%)$ & $8(4.8 \%)$ & $3(2.7 \%)$ & 0.282 \\
\hline Cerebrovascular Disease & $11(4.0 \%)$ & $7(4.2 \%)$ & $4(3.6 \%)$ & 0.521 \\
\hline Rheumatic Heart Disease & $10(3.6 \%)$ & $5(3.0 \%)$ & $5(4.5 \%)$ & 0.376 \\
\hline Chronic Kidney disease & $10(3.6 \%)$ & $9(5.5 \%)$ & $1(0.9 \%)$ & 0.054 \\
\hline Congenital Heart Disease & $8(2.9 \%)$ & $5(3.0 \%)$ & $3(2.7 \%)$ & 0.580 \\
\hline Hypothyroidism & $7(2.5 \%))$ & $2(1.2 \%)$ & $5(4.5 \%)$ & 0.090 \\
\hline Acute Kidney Injury & $6(2.2 \%)$ & $5(3.0 \%)$ & $1(0.9 \%)$ & 0.406 \\
\hline Seizure Disorder & $3(1.1 \%)$ & $3(1.8 \%)$ & 0 & 0.210 \\
\hline Hypertrophic Cardiomyopathy & $2(0.7 \%)$ & $2(1.2 \%)$ & 0 & 0.354 \\
\hline Malignancy & $3(1.1 \%)$ & $3(1.8 \%)$ & 0 & 0.210 \\
\hline Pulmonary Hypertension & $1(0.35 \%)$ & 0 & $1(0.9 \%)$ & 0.404 \\
\hline
\end{tabular}


A total of $15(5.4 \%)$ cases experienced some form of complications during and after the PPI. Most common complication was wound site infection/resuturing. Pocket site hematoma occurred in 3 cases $(1.0 \%)$; all patients were under antiplatlets with 1 under DAPT after acute MI. Wound site infection requiring resuturing occurred in $4(1.4 \%)$ cases but none had incidence of endocarditis and none required replacement of pulse generator or leads. Dislodgement of leads occurred in $3(1.0 \%)$ cases of which, 2 had dislodgement of RV lead in single chamber unit and 1 had dislodgement of right atrial lead in double chamber unit which were refixed after detection. Pneumothorax occurred in 2 cases $(0.7 \%)$ which were managed with chest tube drainage. RV perforation occurred in $3(1 \%)$ cases and all were attributed to stiff TPI lead. 2 cases underwent RV repair and 1 $(0.36 \%)$ died post surgery due to post-operative complication, while other was discharged. 1 case underwent pericardiocentesis and was kept in observation. After pericardial effusion was decreasing and patient's condition was improving, pigtail was removed and patient was discharged.

\section{Discussion}

Pacemaker implantation is the only effective treatment for symptomatic bradycardia. Implantation of a pacemaker has shown to relieve symptoms, improve the quality of life and reduce mortality. ${ }^{1,}$ ${ }^{2}$ Use of permanent pacemaker has been increasing in Nepal in the past several years owing to establishment of more cath labs capable of performing the procedure. Our study shows that among patients receiving PPI, 165 (59.5\%) were male and $112(40.5 \%)$ were female with male to female ratio of 1.47 . Studies published in Nepal by Khanal $\mathrm{J}$ et al ${ }^{9}$, Monib $\mathrm{A}$ et $\mathrm{al}^{10}$ and $\mathrm{Jha} \mathrm{S}$ et $\mathrm{al}^{11}$ showed similar age distribution with male predominance in PPI. Male predominance in PPI was also shown in annual report published by $\mathrm{SGNHC}^{13}$. A study carried out in Australia reported median age of pacemaker recipients was 86 years and $61 \%$ were male ${ }^{14}$. The reason for fewer incidences of female cases might be the less health seeking behavior of female and less investment of society on female patients. The minimum age at PPI was 8 years and $3(1.1 \%)$ cases had PPI at $<20$ years of age which were the cases with congenital heart disease and congenital complete heart block. The maximum age at PPI was 99 years with almost $70 \%$ of cases aged $>60$ years and $51(18.4 \%)$ cases aged $>80$ years. Accumulation of cases in later age ( $>60$ years) might probably be due to incidence of degenerative disease as well as ischemic heart disease (IHD) in this age group of patients.

Dual-chamber pacemakers have been demonstrated to be effective over single chamber pacemakers ${ }^{15}$. However, in our study population single chamber pacemaker was the most frequently used one 228 (82.3\%). Dual chamber units were implanted in only $49(17.7 \%)$ cases. Only 13 women (11.6\%) received dual chamber pacemaker compared with 36 men $(21.8 \%)(\mathrm{P}=0.029)$. Other studies published in Nepal also show similar incidence of single chamber pacemakers over dual chamber ones ${ }^{9,10,13}$. The finding of the study done in Australia is different with our study, which revealed that $74 \%$ of the patients received a dual chamber pacemaker ${ }^{14}$. Main reason for it was financial constraint and even more so in female probably due to gender bias. Similar results regarding gender related difference was found in study done by Khanal $\mathrm{J}$ et $\mathrm{al}^{12}$. Study done by Nowak B et $\mathrm{a}^{16}$ in Germany also showed similar sex differences in dual chamber pacemaker implantation, even more so in old age individuals and in study done by Lamas GA et al in USA ${ }^{17}$, whereas study done by Veerareddy et $\mathrm{al}^{18}$ in USA showed no sex differences in the selection of pacemaker. Increased utilization of pacemakers in male could also be explained by the increased incidence of IHD (clinical/subclinical) in male as evidenced by increased incidence of MI, HTN, DM in male compared to female which might be cause for heart block. In our study, dual chamber units were implanted in younger patients compared to older ones $(\mathrm{p}<0.001)$. Out of total patients receiving dual chamber units only $28.5 \%$ were $>60$ years of age, though almost $70 \%$ of total patients in the study were $>60$ years of age. Studies done by Nowak B et $\mathrm{al}^{16}$ and Veerareddy et $\mathrm{al}^{18}$ also showed increased use of dual chamber pacemakers in younger patients compared to older ones. This might be explained by the fact that older individuals are usually involved in less activity and single chamber pacemaker might be sufficient to produce desired effect without symptoms at that level of activity.

The most common indication for PPI was CHB followed by SSS. Similar findings were noted in study done by Khanal $\mathrm{J}$ et $\mathrm{al}^{9}$ and Jha $\mathrm{S}$ et $\mathrm{a}{ }^{11}$ whereas study done by Monib $\mathrm{A}$ et $\mathrm{al}^{10}$ showed much higher incidence of CHB (87\%) than our study. Annual report of SGNHC showed $65-78 \%$ incidence of CHB but much lesser incidence of SSS (6-9\%) compared to our study ${ }^{13}$. In a study by Veerareddy S et al in USA, SSS $(55 \%)$ was the commonest cause of $\mathrm{PPI}^{18}$. Similar findings were noted in study done in Germany by Nowak B et $\mathrm{al}^{16}$. In another study from Greece AV block (47\%) was the commonest cause of PPI ${ }^{19}$. Less incidence of SSS in our study could be attributed to failure to diagnose SSS due to lack of adequate diagnostic facilities in different centres such as holter compared to $\mathrm{CHB}$ which might be easily picked up in rhythm strip of ECG. In our study, CHB was more common in male patients where as SSS was more common in female. Similar findings was noted in study done by Nowak et al in Germany ${ }^{16}$. This relation of increased CHB in male compared to female might be due to relation of AV block to IHD which is more common in Male than in Female patients. However, annual report published by SGNHC showed similar increased incidence of CHB and SSS in male compared to female ${ }^{13}$.

In our study, 161 (58.1\%) cases had one or more co morbidities. Hypertension was the most common co morbidity present followed by diabetes mellitus and post MI. Post cardiac surgery, DCM and congenital heart disease also accounted for share of cases. Male cases undergoing PPI had more prevalence of Hypertension diabetes mellitus and post myocardial Infarction compared to female cases.

While comparing our findings with the reports from USA and Australia, we found similar results with the incidence of procedural complications reported between $3-6 \%$ and around $50 \%$ of these complications being serious or requiring further treatment ${ }^{20-22}$. Study done in Germany be Nowak B et al also reported similar statistics with pocket hematoma the commonest complication followed by pneumothorax and lead dislodgement. Complication rate was 5.8\% in female and $4.7 \%$ in male where as mortality was $1.4 \%$ in male and $1.2 \%$ in female patients ${ }^{16}$. These findings proved that the service of PPI was effective and relatively safe in our centre.

The limitation of our study is that we collected data retrospectively from hospital records which create room for chance of missing data or data error if not recorded accurately in first hand by operators or staffs. Compiling data from multiple records helped to minimize this possibility. We couldn't analyze long term complication of PPI as patients were not followed up. We also didn't analyze the complications related to age, sex and type of pacemaker implanted which might have helped to create more elaborate data regarding complications. Moreover, being a single centre study, the results may not accurately reflect the whole population.

\section{Conclusion}

Single chamber pacemaker was the most commonly used pacemaker. Dual chamber pacemaker was more common in younger patients. Complete heart block was the most common indication. Permanent pacemaker insertion was effective and relatively safe procedure in MCVTC with few complications. 


\section{Acknowledgement}

I would like to thank Prof Dr Arun Sayami (Head of Department, cardiology), Prof Dr Sunil Chandra Jha and Dr Subarnamani Acharya for continuous support and guidance and also as performers of PPI from the initial periods of establishment of this centre and before this as well.

\section{Conflict of Interest: None}

\section{References}

1. Lamas, G.A., et al., Ventricular pacing or dual-chamber pacing for sinus-node dysfunction. New England Journal of Medicine, 2002. 346(24): p. 1854-1862.

https://doi.org/10.1056/NEJMoa013040

2. Epstein, A.E., et al., ACC/AHA/HRS 2008 guidelines for device-based therapy of cardiac rhythm abnormalities: a report of the American College of Cardiology/American Heart Association Task Force on Practice Guidelines (Writing Committee to Revise the ACC/AHA/NASPE 2002 Guideline Update for Implantation of Cardiac Pacemakers and Antiarrhythmia Devices) developed in collaboration with the American Association for Thoracic Surgery and Society of Thoracic Surgeons. Journal of the American College of Cardiology, 2008. 51(21): p. e1-e62.

3. Elmqvist, R. and A. Senning. An implantable pacemaker for the heart. in Medical Electronics. Proceedings of the Second International Conference on Medical Electronics, Paris. 1959.

4. Ginks, W., A. Leatham, and H. Siddons, Prognosis of patients paced for chronic atrioventricular block. Heart, 1979. 41(6): p. 633-636.

https://doi.org/10.1136/hrt.41.6.633

5. Pacing, B. and E. Group, Recommendations for pacemaker prescription for symptomatic bradycardia. British Heart Journal, 1991. 66(2): p. 185.

https://doi.org/10.1136/hrt.66.2.185

6. Kappenberger, L.J. and L. Herpers, Rate responsive dual chamber pacing. Pacing and Clinical Electrophysiology, 1986. 9(6): p. 987-991.

https://doi.org/10.1111/j.1540-8159.1986.tb06658.x

7. Bernstein, A.D., et al., The NASPE*/BPEG** Generic Pacemaker Code for Antibradyarrhythmia and Adaptive Rate Pacing and Antitachyarrhythmia Devices. Pacing and Clinical Electrophysiology, 1987. 10(4): p. 794-799.

https://doi.org/10.1111/j.1540-8159.1987.tb06035.x

8. Humen, D.P., et al., A pacemaker which automatically increases its rate with physical activity, in Cardiac pacing. 1983, Springer. p. 259-264.

https://doi.org/10.1007/978-3-642-72367-4_39

9. Khanal, J., et al., Clinical Profile and Early Complications after Single and Dual Chamber Permanent Pacemaker Implantation at Manmohan Cardiothoracic Vascular and Transplant Centre, Kathmandu, Nepal. Journal of Nepal Health Research Council.

https://doi.org/10.33314/jnhrc.v0i0.638.
10. Monib, A., Nepal, R., Dhungana, S., et al. Early outcome of permanent pacemaker implantation. Journal of Nobel Medical College, 2018; 7(2), 35-38.

https://doi.org/10.3126/jonmc.v7i2.22304

11. Jha S, A.S., Pahari A. Cardiac pacing at TU Teaching HospitalChanging perspective. Journal of Institute of Medicine. 2007 Jan 21;20(1).

12. Khanal J, P.R., Devkota S, Thapa S, Shrestha A. Gender Differences in Selection of Permanent Pacemaker Implantation at Manmohan Cardiothoracic Vascular and Transplant Centre, Kathmandu, Nepal. Journal of Nobel Medical College. 2015 Sep 1;4(1):15-20.

https://doi.org/10.3126/jonmc.v4i1.13299

13. Annual report, Sahid Gangalal National Heart Centre.2013:p29. 2014:p31. 2015 p27-29.

14. Gillam MH, P.N., Inacio MC, Shakib S, et al. Rehospitalizations for complications and mortality following pacemaker implantation: A retrospective cohort study in an older population. Clinical cardiology. 2018 Nov;41(11):14806. https://doi.org/10.1002/clc.23091

15. Castelnuovo E, S.K., Pitt M, Garside R, Payne E. The effectiveness and cost-effectiveness of dual-chamber pacemakers compared with single-chamber pacemakers for bradycardia due to atrioventricular block or sick sinus syndrome: systematic review and economic evaluation. InNIHR Health Technology Assessment programme: Executive Summaries 2005. NIHR Journals Library. https://doi.org/10.3310/hta9430

16. Nowak, B., et al., Do gender differences exist in pacemaker implantation? results of an obligatory external quality control program. Europace, 2009. 12(2): p. 210-215.

https://doi.org/10.1093/europace/eup312

17. Lamas, G.A., et al., Permanent pacemaker selection and subsequent survival in elderly Medicare pacemaker recipients. Circulation, 1995. 91(4): p. 1063-1069.

https://doi.org/10.1161/01.CIR.91.4.1063

18. Veerareddy S, A.N., Caldito G, Reddy PC. Gender differences in selection of pacemakers: a single-center study. Gender medicine. 2007 Dec 1;4(4):367-73. https://doi.org/10.1016/S1550-8579(07)80066-0

19. Styliadis IH, M.A., Gouzoumas NI, Vassilikos VP, et al. Indications for permanent pacing and pacing mode prescription from 1989 to 2006. Experience of a single academic centre in Northern Greece. Hellenic J Cardiol. 2008 May 1;49(3):15562.

20. Atwater, B.D. and J.P. Daubert, Implantable cardioverter defibrillators: risks accompany the life-saving benefits. Heart. 98(10): p. 764-772.

https://doi.org/10.1136/heartjnl-2012-301853 
21. Dodson JA, L.R., Wang Y, Hammill SC, Varosy P, Curtis JP. Temporal trends in quality of care among recipients of implantable cardioverter-defibrillators: insights from the National Cardiovascular Data Registry. Circulation. $2014 \mathrm{Feb}$ 4;129(5):580-6.

https://doi.org/10.1161/CIRCULATIONAHA.113.003747
22. Russo, A.M., et al., Gender and outcomes after primary prevention implantable cardioverter-defibrillator implantation: findings from the National Cardiovascular Data Registry (NCDR). American heart journal. 170(2): p. 330-338. https://doi.org/10.1016/j.ahj.2015.02.025 